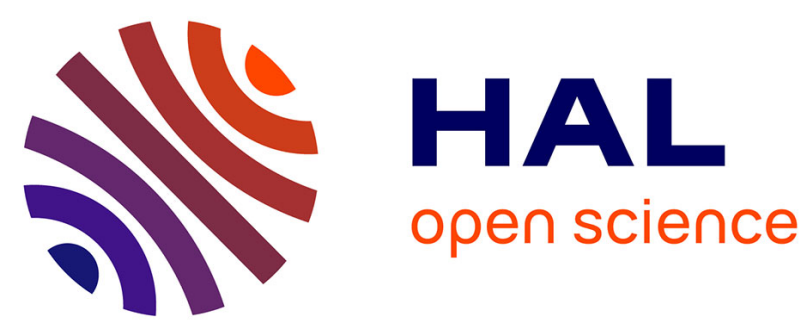

\title{
Neighborhood deprivation and risk of head and neck cancer: A multilevel analysis from France
}

Joséphine Bryere, Gwenn Menvielle, Olivier Dejardin, Ludivine Launay, Florence Molinie, Isabelle Stücker, Danièle Luce, Guy Launoy

\section{To cite this version:}

Joséphine Bryere, Gwenn Menvielle, Olivier Dejardin, Ludivine Launay, Florence Molinie, et al.. Neighborhood deprivation and risk of head and neck cancer: A multilevel analysis from France. Oral Oncology, 2017, 71, pp.144-149. 10.1016/j.oraloncology.2017.06.014 . hal-01578588

HAL Id: hal-01578588

https://hal-univ-rennes1.archives-ouvertes.fr/hal-01578588

Submitted on 14 Nov 2019

HAL is a multi-disciplinary open access archive for the deposit and dissemination of scientific research documents, whether they are published or not. The documents may come from teaching and research institutions in France or abroad, or from public or private research centers.
L'archive ouverte pluridisciplinaire HAL, est destinée au dépôt et à la diffusion de documents scientifiques de niveau recherche, publiés ou non, émanant des établissements d'enseignement et de recherche français ou étrangers, des laboratoires publics ou privés. 


\section{Neighborhood deprivation and risk of head and neck cancer:}

\section{A multilevel analysis from France}

Joséphine Bryere ${ }^{1^{*}}$, Gwenn Menvielle ${ }^{2}$, Olivier Dejardin ${ }^{1}$, Ludivine Launay ${ }^{1}$, Florence Molinie ${ }^{3}$, Isabelle Stucker ${ }^{4}$, Daniele Luce ${ }^{5}$, Guy Launoy ${ }^{1}$ and ICARE group.

1 "Cancers \& Préventions" U1086 INSERM-UCN, team Labeled « Ligue Contre le Cancer », Centre François Baclesse, Avenue Général Harris, 14076 Caen, France.

${ }^{2}$ Sorbonne Université, UPMC Univ Paris 6, INSERM, Institut Pierre Louis d’Epidémiologie et Santé Publique (IPLESP UMRS 1136) 75012 Paris, France.

${ }^{3}$ Registre des cancers de Loire-Atlantique et Vendée, 50 route de Saint-Sébastien, 44093 Nantes cedex 1, France.

${ }^{4}$ INSERM UMRS 1018, Centre de Recherche en Epidémiologie et santé des Populations, 15/16 avenue Paul Vaillant Couturier, 94807 Villejuif, France.

5 INSERM U1085, IRSET, Faculté de Médecine, Campus de Fouillole 97154 Point-à-Pitre, France.

Corresponding author: Joséphine Bryere ; josephine.bryere@inserm.fr, U1086 INSERM-UCN, Centre François Baclesse, Avenue du Général Harris, 14076 Caen, France ; Tel: +332 314586 11, Fax: +332 3145 8630. 


\section{Abstract}

Background While it is known that cancer risk is related to area-level socioeconomic status, the extent to which these inequalities are explained by contextual effects is poorly documented especially for head and neck cancer.

Methods A case-control study, ICARE, included 2415 head and neck cancer cases and 3555 controls recruited between 2001 and 2007 from 10 French regions retrieved from a general cancer registry. Individual socioeconomic status was assessed using marital status, highest educational level and occupational social class. Area-level socioeconomic status was assessed using the French version of the European Deprivation Index (EDI). The relationship between both individual and area-based socioeconomic level and the risk of head and neck cancer was assessed by multilevel analyses.

Results A higher risk for head and neck cancer was found in divorced compared with married individuals $(\mathrm{OR}=2.14,95 \% \mathrm{Cl}=1.78-2.57)$, for individuals with a basic school-leaving qualification compared with those with higher education ( $\mathrm{OR}=4.5595 \% \mathrm{Cl}=3.72-5.57)$, for manual workers compared with managers $(\mathrm{OR}=4.91,95 \% \mathrm{Cl}=3.92-6.15)$ and for individuals living in the most deprived areas compared with those living in the most affluent ones $(\mathrm{OR}=1.98,95 \% \mathrm{Cl}=1.64-2.41)$. The influence of area-level socioeconomic status measured by EDI remained after controlling for individual socioeconomic characteristics (OR=1.51; 95\% confidence interval: $1.23-1.85, \mathrm{p}$-value $=0.0003)$.

Conclusions The role of individual socioeconomic status in the risk of head and neck cancer is undeniable, although contextual effects of deprived areas also increase the susceptibility of individuals developing the disease.

Keywords Upper aerodigestive tract cancer, socioeconomic status, neighborhood deprivation, multilevel analysis, case-control studies. 


\section{Introduction}

Social inequalities in cancer incidence have been reported worldwide and for many cancer sites. An increased incidence in deprived populations has been observed for lung [1-4,] head and neck [1,3-5], liver[1,5], cervix[1,4-6], bladder [4], stomach $[1,5]$ and esophagus $[1,5,7]$ and an increased incidence in affluent populations has been observed for breast $[1,4,5,8]$ and prostate cancer $[1,4,5,9]$, and for melanoma, $[1,4,5,10]$. The influence of area-based socioeconomic level on the incidence of cancer is well documented in the literature but the underlying mechanisms that create these associations are rarely addressed.

It is currently unclear whether the higher incidence in disadvantaged areas is correlated with the higher proportion of disadvantaged individuals in these areas (composition effect) or if other aspects specific to the areas (positive or negative externalities) are associated with cancer risk (context effect). For example, regarding context effects, the social environment of the residence area is thought to have an influence on the percentage of smokers [11]. It has also been demonstrated that lower neighborhood socioeconomic status and higher convenience store concentration can be associated with a higher proportion of smokers after accounting for individual characteristics [12]. Others suggest that people living in the most deprived areas in some countries have greater exposure to environmental pollution [13]. More generally, the lives and health of individuals are affected not only by their personal characteristics but also by characteristics of the social groups (service availability, environmental exposition, job, education and leisure opportunities) to which they belong.

It appears essential to estimate the association between area-based socioeconomic level and incidence after controlling for individual socioeconomic variables to understand the extent of both composition effects and contextual effects. To our knowledge, while four studies of this type have focused on breast cancer [8,14-16], three on prostate cancer [15-17], three on colorectal cancer $[16,18,19]$ and three on lung 
cancer $[16,17,20]$ none has investigated head and neck cancer despite being one of the sites most affected by social inequalities in cancer incidence [1].

The objective of this study was to explore the hypothesis that a contextual effect could explain part of the higher incidence of head and neck cancers in deprived areas. This was done by jointly evaluating the influence of individual and area-based socioeconomic level on the incidence of cancer by performing a multilevel analysis [21] of data from the case-control study ICARE.

\section{Materials and methods}

\section{Study population}

The ICARE study design has been previously published [22]. Briefly, it is a multicenter case-control study on lung and head and neck cancers in the general population conducted between 2001 and 2007 in 10 French regions retrieved from a general cancer registry. The registry comprises approximately $13 \%$ of the French population ( 7.6 million inhabitants). Only histologically confirmed cases aged $\leq 75$ at the time of diagnosis identified between 2001 and 2007 and living in one of the 10 regions of the study were eligible. 2415 cases of head and neck cancer were included. Controls were selected by list-assisted random digit dialing sampling, in the same "départements" as the cases, using incidence density sampling method. Recruitment of controls was done by telephone by a polling institute experienced in this type of procedure. Controls were frequency-matched to the cases by sex, age (in 4 categories: less than $40,40-54,55-64,>65$ ) Additional stratification was used to achieve a distribution by socioeconomic status among controls comparable to that of the general population. 3555 control individuals were interviewed. The distribution of the main occupational and economic activity characteristics of the active population of the regions in the study is similar to their distribution in France [22]. 


\section{Individual socioeconomic variables}

Specifically trained investigators interviewed the subjects. The questionnaire included a demographic section consisting of variables: age, marital status and educational attainment. It also included a history of occupied professions. Marital status (married, widower, single, divorced), educational attainment (Higher degree meaning college degree, A-level allowing for university entrance, technician level meaning the obtaining of a technical qualification, basic school meaning compulsory minimum level), and category of longest period of occupation (manager meaning an individual with management responsibility, farmer meaning person engaged in agriculture, mid-level manager between managers and employees, employee performing office tasks, artisan meaning a skilled manual worker in a particular craft, manual worker performing manual tasks) during one's lifetime were used to assess socioeconomic status at the individual level.

\section{Area-based socioeconomic variables}

The last known address of the cases and controls was geocoded and assigned to an IRIS (Ilots Regroupés pour I'Information Statistique), the smallest French area for which census data are available. Deprivation level of each IRIS was assessed using the EDI (European Deprivation Index) calculated from the 2007 census [23]. The methodology used an individual deprivation indicator from the conceptual definition of deprivation and selected ecological census variables that are the most closely related to the individual deprivation indicator in the European Union Statistics on Income and Living Conditions tool. This was available as a continuous variable, increasing from -17.35 to 51.12 . A categorical version of the EDI (quintiles calculated at the French level) was used. Owing to poor health, some subjects (257 cases and 74 controls) were interviewed using a shorter version of the questionnaire that did not include the residential history. In addition, because the geocoding process required the exact address of the individual to assign geographic coordinates in space (latitude, longitude) and then assign an IRIS, 227 cases and 282 controls 
were excluded because their address was incomplete. The final database included 1931 head and neck cancer cases and 3199 controls (Table 1). The subjects in the study were distributed in 2918 IRIS.

\section{Statistical analysis}

To study the relationship between socioeconomic level and risk of head and neck cancer, we used multilevel analyses justified by the non-independence of observations of subjects from the same geographical unit. This was done because of the hierarchical structure of individual data (level 1) and socioeconomic area-based data (level 2) [24].

- Step 0: Detection of potential existence of a 'group' effect

The first step of the multilevel analysis is based on analyzing the empty model without any explanatory variable. It contains only the random effects at the IRIS level and can detect the potential existence of a 'group' effect, which is also known to be the context effect on the dependent variable, i.e., the risk.

To verify the existence of a context effect, it is necessary to test the null hypothesis that the variance called level 2 variance (V2) is null. V2 quantifies the change in risk of one IRIS to another depending on the characteristics of IRIS. If this hypothesis is rejected, the multilevel model is justified.

- Step 1: Introduction of individual explanatory variables (model 1).

The second step is to add to model 0 the individual variables (marital status, educational attainment, occupational classification) related to the dependent variable in univariate analyses with a $5 \%$ threshold.

We tested whether variations between IRISs were still persistent after adding individual-level variables and observed if the V2 declined with the addition of these variables. If it was the case, this would indicate that certain characteristics of the IRIS (context effect) were associated with the likelihood of having cancer. 
The addition of these individual variables can also identify a possible composition effect. A composition effect exists if the V2 decreases, indicating that some of the variations between the IRISs are due to differences in composition in terms of individual characteristics.

- Step 2: Introduction of the area-based explanatory variable (model 2).

The area-based variable EDI is added to model 1 if it is related to the risk of developing a cancer with a $5 \%$ threshold.

The analyses were performed using SAS version 9.3.

\section{Results}

Table 1 summarizes the individual and collective characteristics of individuals. The first four columns show the distribution of cases and controls according to the individual and area-based variables. The $5^{\text {th }}$ and $6^{\text {th }}$ columns present the results of the univariate regression models of status case/control of each variable independently while adjusting for sex, age and for the IRIS random intercept to examine each association.

Single or divorced individuals were more likely to develop head and neck cancer than married individuals with A-level, a technician level or a basic school-leaving qualification were more likely to have head and neck cancer than those with higher education. Individuals who were middle managers, employees, artisans and manual workers were a higher risk of developing head and neck cancer than managers (Table 1). Regarding the area-based socioeconomic variable, residing in a more deprived IRIS was associated with a higher risk of head and neck cancer, the highest risk being that of the most disadvantaged group compared with the most affluent one (OR=1.98, 95\% $\mathrm{Cl}=1.64-2.41)$.

In model 0 (Table 2$)$, the change in risk between IRISs $(\mathrm{V} 2=0.19)$ was relatively low, but the variation was observed ( $p=0.0022$ ), which justified the use of multilevel models. In model 1 , V2 declined by $14.94 \%$ after 
the addition of individual variables to model 0 . The differences between IRISs were lower when adjusted for individual variables, which highlighted the presence of a composition effect. Risk disparities between IRISs were explained at least partly by individual socioeconomic factors.

In model 2 with individual and area-based variables (model 2), the influence of area-level socioeconomic status as measured by EDI remained after controlling for individual socioeconomic status (OR=1.51; $95 \%$ confidence interval: $1.23-1.85, \mathrm{p}$-value $=0.0003)$. This highlighted the persistence of the context effect after adjusting for individual variables. Adding the deprivation index reduced the variance between IRISs by $19.92 \%$ (from 0.1914 to 0.1596 ) compared with model 0 and by $2.01 \%$ (from 0.1628 to 0.1596 ) compared with model 1 . Among the social disparities of risk, $95 \%$ were explained by a composition effect and $5 \%$ by a context effect i.e. by the characteristics of the IRIS, after taking into account the fact that disadvantaged people tend to live in the same places.

The test for cross-level interactions between the individual socioeconomic variables and area-based deprivation score on head and neck cancer risk showed no meaningful interactions.

\section{Discussion}

Individual-level deprivation measured using marital status, educational level, and occupational social class was associated with a higher risk of head and neck cancer. Area-level socioeconomic status as measured by the EDI was also associated with a higher risk of head and neck cancer. An important part of the association between area-level deprivation and head and neck cancer risk is compositional, meaning that people living in lower socioeconomic areas are themselves of lower socioeconomic status and are at increased risk of disease regardless of where they live. However, the association between area deprivation and cancer risk remained after controlling for individual socioeconomic status, meaning that the risk of head and neck cancer was potentially influenced by contextual factors. 
Previous studies have examined the simultaneous impact of socioeconomic level measured at both the individual and area-based level, but none has examined the relationship with the incidence of head and neck cancer. Therefore, our results cannot be compared with those in the literature. Previous studies addressed prostate, breast, colon-rectum, and lung cancer, and most of them concluded that contextual factors had an effect after adjusting for individual socioeconomic level.

A study conducted by Meijer et al.[15] in Denmark between 2004 and 2008 reported that area characteristics were of greater importance in the incidence of lung cancer. Another study conducted by $\mathrm{Li}$ et al. [20] in Sweden between 2000 and 2010 found that neighborhood-level deprivation remained associated with lung cancer incidence after adjusting for individual-level sociodemographic variables and comorbidities.

Hastert et al. [16] in the United States between 2000 and 2002 observed that after controlling for demographics and for individual educational level and household income, the association between arealevel socioeconomic status and prostate and breast cancer incidence didn't exist. Living in areas with the lowest socioeconomic status was associated with higher lung and colorectal cancer incidence. These results suggest that there are moderate-to-large associations between area-level socioeconomic status and specific cancer outcomes that are not completely explained by individual socioeconomic status.

A study conducted by Sanderson et al. [17] between 2000 and 2002 in the United States that focused on prostate cancer risk found that after adjusting for race, age, geographic region, and prostate-specific antigen testing, men with a college degree were at reduced risk for prostate cancer, as were men in the highest quartile of area-level socioeconomic status The independent negative associations persisted when assessing individual-level and area-level socioeconomic status simultaneously.

Webster et al. [14] studied this hypothesis on breast cancer. The results for models including both measures were consistent with a contextual effect of socioeconomic status on the risk of breast cancer 
regardless of individual socioeconomic status. Another conducted by Robert et al. [8] found that after controlling for individual education and other individual risk factors, women were at elevated risk for breast cancer if they lived in the highest socioeconomic communities compared with those living in the lowest socioeconomic communities.

Finally, two studies focused on colorectal cancer. The first one conducted by Doubeni et al. [18] found that socioeconomic status, assessed by either individual-level education or neighborhood measures in a multilevel model, was associated with the risk of colorectal cancer even after controlling for other risk factors. Another one conducted by Kim et al. [19] focused more on behavioral pathways and found that living in a higher-SES neighborhood may protect against colorectal cancer in higher-educated women, and that the association was mediated by selected behavioral risk factors.

These results show consistency with our findings despite focusing on different cancer sites. There are no established standards for measuring area-based social level, making it difficult to directly compare results between studies. Even though the role of individual socioeconomic status in cancer incidence has been previously demonstrated, and is confirmed in the present study, the potential involvement of the characteristics of deprived areas cannot be excluded.

It has been hypothesized that residents of deprived neighborhoods have poorer access to high-quality food environments and to sports facilities, and have greater access to tobacco and alcohol outlets [25]. A study conducted by Black et al. [26], confirmed the finding that neighborhoods vary in terms of factors that could be expected to influence diet and exercise, including the price and availability of healthy food, and the number, proximity, and types of food stores available. Another study found that tobacco outlets were more densely located in areas of higher socioeconomic deprivation [27]. The same could apply to alcohol because another study found that the most deprived neighborhoods had substantially higher levels of alcohol outlet density than the least deprived ones ( $45.5 \%$ vs $14.8 \%$, respectively) [28]. However, these 
studies were conducted in the United States and in New Zealand where the social context is probably different from that in France, and where unfortunately no such study has been carried out.

Other possible mechanisms potentially link deprived areas to cancer risk. One possible pathway could be the psychological stress induced by certain characteristics of deprived areas, including higher population density, vandalism, criminality, excessive noise, economic, education and occupational opportunities. Stress is a condition of the mind-body interaction and a factor in the expression of disease that differs among individuals. It is not just dramatic stressful events are burdensome, but rather the many events of daily life that elevate and sustain the activities of physiological systems and cause sleep deprivation, overeating and other health-damaging behaviors. These all culminate toward feeling "stressed out". Over time, this results in wear and tear on the body, called "allostatic load", and it reflects not only the impact of life experiences but also genetic load, individual lifestyle habits reflecting items such as diet, exercise, substance abuse, alcohol and smoking and developmental experiences that set life-long patterns of behaviors and physiological reactivity. In the long run, allostatic load causes changes in the body that can lead to disease [29]. Until now, this hypothesis has only been demonstrated in cardiovascular diseases [30].

Our study has some limitations. Despite adjusting for the multilevel model with multiple individual socioeconomic variables such as marital situation, higher educational level, and occupation, the remaining association could be at least partly due to other socioeconomic variables like income and wealth, which was not recorded in the questionnaire. The ICARE study is a multicenter case-control study in the general population ensuring representativeness and good quality data. However, the number of subjects per IRIS is low, which reduces the statistical power of the analysis. The subjects of the study were interviewed by specifically trained investigators, but we cannot exclude a potential response bias in the data. A selection bias cannot be excluded either in this type of study. Finally, the area-based socioeconomic variable was 
measured at the inclusion of the subjects, using their current address but ignoring their history of geographical mobility, which could be between two IRISs with different deprivation indices. Misclassification of the EDI quintile could occur if subjects were placed in the wrong IRIS with a different quintile than the recorded IRIS.

The strengths of the study include diagnostic confirmation obtained from general cancer registries. Because diagnosis and individual data collection for the registries was done by specifically trained investigators and not by questionnaires sent by mail, response bias and selection bias were reduced, thus ensuring good reliability. This allowed us to include three measures of individual-level socioeconomic status.

To our knowledge, this is the first study to explore the hypothesis of a contextual effect explaining part of the higher incidence of head and neck cancers in deprived areas. The role of individual socioeconomic status mediated by health-damaging behaviors is undeniable but the contextual effects of deprived areas also increase the susceptibility of individuals to develop the disease. In addition to measures focused on the behaviors of deprived individuals, health care policies should also consider improving their living environment.

Acknowledgments This work was supported by the Fondation de France, the French National Research Agency (ANR), the Fondation for Medical Research (FRM), the French Institute for Public Health Surveillance (Institut de veille sanitaire, InVS), The Health and Sport department (Direction Générale de la Santé et des Sports), Organization for the Research on Cancer (Association pour la Recherche sur le Cancer, ARC), Ministère du travail, de la Solidarité et de la Fonction Publique (Direction Générale du Travail), and ANSES (Agence Nationale de Sécurité Sanitaire de l'alimentation, de l'environnement et du travail).

\section{References}


1- Boscoe FP, Johnson CJ, Sherman RL, Stinchcomb DG, Lin G, Henry KA. The relationship between area poverty rate and site-specific cancer incidence in the United States. Cancer 2014; 120: 21912198

2- Hystad P, Carpiano RM, Demers PA, Johnson KC, Brauer M. Neighbourhood socioeconomic status and individual lung cancer risk: Evaluating long-term exposure measures and mediating mechanisms. Soc Sci Med 2013; 97: 95-103

3- Sharpe KH, McMahon AD, Raab GM, Brewster DH, Conway DI. Association between socioeconomic factors and cancer risk: a population cohort study in Scotland (1991-2006). PloS one 2014; 9: e89513

4- Eberle A, Luttmann S, Foraita R, Pohlabeln H. Socioeconomic inequalities in cancer incidence and mortality - a spatial analysis in Bremen, Germany. Public Health 2010; 18: 227-235

5- Dalton S, Steding-Jessen M, Enlgholm G, Schuz J, Olsen JH. Social inequality in incidence of and survival from lung cancer in a population-based study in Denmark, 1994-2003. Eur J Cancer 2008; 44: $2074-2085$

6- Benard VB, Johnson CJ, Thompson TD, et al. Examining the association between socioeconomic status and potential human papillomavirus-associated cancers. Cancer 2008; 113: 2910-2918

7- Levi Z, Kark JD, Shamiss A, et al. Body mass index and socioeconomic status measured in adolescence, country of origin, and the incidence of gastroesophageal adenocarcinoma in a cohort of 1 million men. Cancer 2013; 119: 4086-4093

8- Robert SA, Strombom I, Trentham-Dietz A et al. Socioeconomic risk factors for breast cancer. Distinguishing individual and community level effects. Epidemiol 2004; 15:442-450

9- Cheng I, Witte JS, McClure LA, et al. Socioeconomic status and prostate cancer incidence and mortality rates among the diverse population of California. Cancer Causes Control 2009; 20: 14311440 
10- Hausauer AK, Swetter SM, Cockburn MG, Clarke CA. Increases in melanoma among adolescent girls and young women in California: trends by socioeconomic status and UV radiation exposure. Arch Dermatol 2011; 147: 783-789

11- Karvonen S, Sipila P, Martikainen P, Rahkonen O, Laaksonen M. Smoking context - a multilevel approach to smoking among females in Helsinki. BMC Public Health 2008; 8: 134

12- Chuang YC, Cubbin C, Ahn D, Winkelby MA. Effects of neighbourhood socioeconomic status and convenience store concentration on individual level smoking. J Epidemiol Community Health 2005; 59: 568-573.

13- Naess O , Piro FN, Nafstad P, Smith GD, Leyland AH. Air pollution, social deprivation, and mortality. A multilevel cohort study. Epidemiol 2007; 18: 686-694

14- Webster TF, Hoffman K, Weinberg J, Vieira V, Aschengrau A. Community and individual level socioeconomic status and breast cancer risk: Multilevel modeling on Cape Cod, Massachusetts. Environ Health Perspect 2008; 116: 1125-1129

15- Meijer M, Bloomfield K, Engholm G. Neighbourhoods matter too: The association between neighbourhood socioeconomic position, population density and breast, prostate and lung cancer incidence in Denmark between 2004 and 2008. J Epidemiol Community Health 2013; 67: 6-13

16- Hastert TA, Beresford SA, Sheppard L, White E. Disparities in cancer incidence and mortality by area-level socioeconomic status: A multilevel analysis. J Epidemiol Community Health 2015; 69, 168-176.

17- Sanderson M, Coker AL, Perez A, Du XL, Peltz G, Fadden MK. A multilevel analysis of socioeconomic status and prostate cancer risk. Ann Epidemiol 2006; 16: 901-907

18- Doubeni CA, Laiyemo AO, Major JM, et al. Socioeconomic status and the risk of colorectal cancer: An analysis of more than a half million adults in the National Institutes of Health-AARP Diet and Health Study. Cancer 2012; 118: 3636-3644. 
19- Kim D, Masyn KE, Kawachi I, Laden F, Colditz GA. Neighborhood socioeconomic status and behavioral pathways to risks of colon and rectal cancer in women. Cancer 2010; 116: 4187-4196

20- Li X, Sundquist J, Zöller B, Sunquist K. Neighborhood deprivation and lung cancer incidence and mortality: a multilevel analysis from Sweden. J Thorac Oncol 2015; 10, 256-263

21- Chaix B, Chauvin P. L'apport des modèles multiniveau dans l'analyse contextuelle en épidémiologie sociale : une revue de la littérature. Rev Epidemiol Sante Publique 2002;50(5)48999.

22- Luce D, Stücker I and ICARE study group. Investigation of occupational and environmental causes of respiratory cancers (ICARE): A multicenter, population-based case-control study in France. BMC Public Health 2011; 11: 928

23- Pornet C, Delpierre C, Dejardin O, et al. Construction of an adaptable European transnational ecological deprivation index : The French version. J Epidemiol Community Health 2012; 66: 982989

24- Diez Roux A. A glossary for multilevel analysis. J Epidemiol Community Health 2002; 56: 588-594

25- Shortt NK, Tisch C, Pearce J et al. A cross-sectional analysis of the relationship between tobacco and alcohol outlet density and neighbourhood deprivation. BMC Public Health 2015; 15:1014

26- Black JL, Macinko J. Neighborhoods and obesity. Nutrition reviews 2008; 66: 2-20

27- Marsh L, Doscher C, Robertson LA. Characteristics of tobacco retailers in New Zealand. Health Place 2013; 23: 165-170

28- Pollack CE, Cubbin C, Ahn D, Winkleby M. Neighbourhood deprivation and alcohol consumption: does the availability of alcohol play a role? Int J Epidemiol 2005, 34, 772-780

29- McEwen BS. Protective and damaging effects of stress mediators: Central role of the brain. Dialogues Clin Neurosci 2006; 8: 367 
30- Krantz DS, McCeney MH. Effects of psychological and social factors on organic disease: Critical assessment of research on coronary heart disease. Annu Rev Psychol 2002; 53: 341-369. 
Table 1: Individual and aggregate characteristic of study population and their association with UADT cancer

\begin{tabular}{lllll}
\hline $\begin{array}{l}\text { Case } \\
\text { (n=1931) }\end{array}$ & & $\begin{array}{l}\text { Control } \\
(n=3199)\end{array}$ & & \\
Number & Percentage & Number $\quad$ Percentage $\quad$ OR $^{\text {a }}$ (Cl 95\%) & p-value
\end{tabular}

\begin{tabular}{|c|c|c|c|c|c|c|}
\hline \multicolumn{7}{|l|}{ Individual variables } \\
\hline Marital status & & & & & & $<0.0001$ \\
\hline Married & 1293 & 67.03 & 2448 & 76.60 & 1 & \\
\hline Widower & 101 & 5.24 & 219 & 6.85 & $1.07(0.82-1.40)$ & \\
\hline Single & 215 & 11.15 & 237 & 7.42 & $1.75(1.42-2.16)$ & \\
\hline Divorced & 320 & 16.59 & 292 & 9.14 & $2.14(1.78-2.57)$ & \\
\hline Educational attainment & & & & & & $<0.0001$ \\
\hline Higher degree & 211 & 11.13 & 828 & 26.23 & 1 & \\
\hline A-level & 147 & 7.76 & 366 & 11.59 & $1.67(1.30-2.16)$ & \\
\hline Technician level & 876 & 46.23 & 1267 & 40.13 & $2.84(2.37-3.41)$ & \\
\hline Basic school & 661 & 34.88 & 696 & 22.05 & $4.55(3.72-5.57)$ & \\
\hline Occupational classification & & & & & & $<0.0001$ \\
\hline Manager & 119 & 6.25 & 552 & 17.33 & 1 & \\
\hline Farmer & 52 & 2.73 & 189 & 5.93 & $1.28(0.88-1.87)$ & \\
\hline Mid-level manager & 206 & 10.82 & 634 & 19.90 & $1.53(1.18-1.99)$ & \\
\hline Employee & 310 & 16.28 & 601 & 18.86 & $2.87(2.22-3.73)$ & \\
\hline Artisan & 124 & 6.51 & 157 & 4.93 & $3.83(2.78-5.28)$ & \\
\hline Manual worker & 1093 & 57.41 & 1053 & 33.05 & $4.91(3.92-6.15)$ & \\
\hline \multicolumn{7}{|l|}{ Area-based variable } \\
\hline EDI quintile & & & & & & $<0.0001$ \\
\hline 1 (most affluent)marital & 334 & 17.39 & 726 & 22.82 & 1 & \\
\hline 2 & 403 & 20.98 & 660 & 20.75 & $1.14(0.93-1.38)$ & \\
\hline 3 & 375 & 19.52 & 585 & 18.39 & $1.45(1.19-1.76)$ & \\
\hline 4 & 329 & 17.13 & 645 & 20.28 & $1.44(1.19-1.75)$ & \\
\hline 5 (most deprived) & 480 & 24.99 & 565 & 17.76 & $1.98(1.64-2.41)$ & \\
\hline
\end{tabular}

a Univariate analyses adjusted for age and sex, OR=Odd ratio 
Table 2: Influence of socioeconomic level on risk of UADT cancer, multilevel analysis

\begin{tabular}{lllllll}
\hline Model 0 & Model 1 & & & Model 2 & \\
& OR $^{\mathrm{a}}$ & $\mathrm{Cl}^{\mathrm{b}}$ 95\% & $\mathrm{p}$-value & ORa & $\mathrm{Cl}^{\mathrm{b}}$ 95\% & $\mathrm{p}$-value
\end{tabular}

\begin{tabular}{|c|c|c|c|c|c|c|c|}
\hline \multicolumn{8}{|l|}{ Individual variables } \\
\hline Age; mean & & 0.99 & $0.99-1.00$ & 0.1119 & 0.994 & $0.987-1.001$ & 0.0850 \\
\hline Sex & & & & $<0.0001$ & & & $<0.0001$ \\
\hline Man & & 1 & & & 1 & & \\
\hline Woman & & 0.64 & $0.53-0.78$ & & 0.636 & $0.527-0.768$ & \\
\hline Marital status & & & & $<0.0001$ & & & $<0.0001$ \\
\hline Married & & 1 & & & 1 & & \\
\hline Widower & & 0.89 & $0.67-1.18$ & & 0.859 & $0.649-1.137$ & \\
\hline Single & & 1.61 & $1.29-2.00$ & & 1.579 & $1.265-1.973$ & \\
\hline Divorced & & 1.96 & $1.62-2.37$ & & 1.905 & $1.571-2.311$ & \\
\hline Educational attainment & & & & $<0.0001$ & & & $<0.0001$ \\
\hline Higher degree & & 1 & & & 1 & & \\
\hline A-level & & 1.33 & $1.02-1.74$ & & 2.311 & $0.964-1.651$ & \\
\hline Technician level & & 1.64 & $1.32-2.03$ & & 1.590 & $1.280-1.975$ & \\
\hline Basic school & & 2.36 & $1.86-3.01$ & & 2.245 & $1.761-2.862$ & \\
\hline Occupational classification & & & & $<0.0001$ & & & $<0.0001$ \\
\hline Manager & & 1 & & & 1 & & \\
\hline Farmer & & 0.81 & $0.54-1.21$ & & 0.800 & $0.530-1.207$ & \\
\hline Mid-level manager & & 1.31 & $0.10-1.72$ & & 1.339 & $1.021-1.757$ & \\
\hline Employee & & 2.00 & $1.50-2.66$ & & 1.965 & $1.475-2.618$ & \\
\hline Artisan & & 2.74 & $1.94-3.86$ & & 2.724 & $1.930-3.843$ & \\
\hline Manual worker & & 3.06 & 2.34-3.99 & & 3.041 & $2.328-3.973$ & \\
\hline \multicolumn{8}{|l|}{ Area-based variable } \\
\hline EDI quintile & & & & & & & 0.0003 \\
\hline 1 (most affluent) & & & & & 1 & & \\
\hline 2 & & & & & 1.049 & $0.852-1.292$ & \\
\hline 3 & & & & & 1.316 & $1.070-1.619$ & \\
\hline 4 & & & & & 1.281 & $1.044-1.571$ & \\
\hline 5 (most deprived) & & & & & 1.509 & $1.231-1.850$ & \\
\hline V2 & 0.1914 & 0.1628 & & & 0.1596 & & \\
\hline Standard Error & 0.0671 & 0.0740 & & & 0.0745 & & \\
\hline
\end{tabular}

${ }^{\mathrm{a}}$ Odd ratio; ${ }^{\mathrm{b}}$ Confidence Interval 